\title{
Evaluation of Electricity Demand Response from the Perspective of Marketization
}

\author{
Dong Jun, Sun Xu, Dou Xihao \\ School of Economics and Management, North China Electric Power University, Beijing, China \\ Email address: \\ dongjun624@126.com (Dong Jun), 1551517314@qq.com (Sun Xu),2268728128@qq.com (Dou Xihao)
}

To cite this article:

Dong Jun, Sun Xu, Dou Xihao. Evaluation of Electricity Demand Response from the Perspective of Marketization. Journal of Electrical and Electronic Engineering. Vol. 5, No. 4, 2017, pp. 141-148. doi: 10.11648/j.jeee.20170504.15

Received: June 15, 2017; Accepted: June 29, 2017; Published: July 24, 2017

\begin{abstract}
China electricity market reform will have a far-reaching impact on demand response, The demand response under the market mechanism is an important tool to alleviate the contradiction between power supply and demand, reduce the peak load and promote energy conservation and emission reduction. Based on the analysis of the operation mode of foreign demand response, this paper designs the demand response mechanism under the Chinese market mechanism. Based on the cost-benefit analysis method, the economic value generated by the implementation of the demand response is evaluated. The research results can provide decision support for demand response mechanism design and demand response mining in power market reform.
\end{abstract}

Keywords: Demand Response, Electricity Market, Operational Mechanism, Value Assessment

\section{Introduction}

Demand response (DR) refers to the power user for the DR implementation agencies to release the price signal or incentive mechanism to respond to and change their own power mode of market-oriented behavior [1]. Demand response refers to the different degree of marketization, through technical and economic, administrative, legal and other means to encourage and guide users to change the conventional way of electricity, scientific and rational use of electricity to promote the optimal allocation of power resources to ensure that the power system is safe and economic operation of the management work [2].

In recent years, in the context of the ever-fissile structure of the power industry, electricity demand response in the developed countries stand out, and get large-scale practice. Only in 2010, the US regional transmission organization and independent system operators to implement the demand response project to provide $27189 \mathrm{MW}$ demand response resources, accounting for about $3 \%$ of the installed capacity of the US electricity [3]. It can be said that the electricity demand response has become an important tool to alleviate the contradiction between power supply and demand, promote the practice of energy saving and emission reduction policies, and reduce the demand and guide demand [4].

DR to adapt to the development of China's power system requirements, not only help to promote the efficient operation of power systems, and the entire power industry development, energy-saving emission reduction and economic development are of great significance. As suggested by the US Department of Energy's report to the US Congress, "we need to strengthen research on the analysis and quantitative assessment of demand response, so that policymakers and users can better evaluate the benefits that demand responses can bring" [5]. In view of this, this paper introduces the operation mode of foreign DR, and designs the implementation mode of China's demand response, and makes a data calculation on the implementation value of DR which can provide reference for China to implement DR.

\section{Experience of Foreign Demand Response Operation}

China's current demand response is still in the stage of exploration, in the context of the reform of electricity market, learn from the foreign power market demand for the implementation of the response and management is of great significance. 
In the foreign electricity market, the US PJM power market demand response mechanism is more mature, load aggregators and distribution companies etc. any party that can aggregate demand-side resources to participate in market operations can become a reduction service provider. They as the system operators and demand side resources to the middleman, to achieve the flow of information and capital. Demand-side resources can participate in a variety of load response plans, including the PJM emergency response program, the economic load response program and participate in the day before and the reserve market and synchronous backup markets and frequency modulation markets [6].

Japan has a sound energy-saving organization and management system: The first layer is based on the Ministry of Economy, Trade and Industry and the local economy and industry bureau, which is mainly responsible for the energy conservation management in the industrial field and realizing the integration of the administrative management of energy and economic industries.

The second floor is a professional energy conservation organization, responsible for organizing, managing and promoting application research projects; The third floor is energy-saving designated factories and energy-saving products manufacturers and distributors, responsible for the implementation of the energy policy measures [7].

Most of the demand-side resources used in Europe are dominated by large-scale power users. The UK electricity market offers a variety of time-of-use price tariff rates to motivate users to participate in demand responses and organize demand-side resources through interruptible load contracts to participate in short-term backup services, fast standby and stable grid frequency response. France uses time-of-use price to organize demand-side resources to participate in the market and to set the threshold for market access. In Spain, the price and incentive mechanisms for demand responses are broken down into multiple. The energy market divides the time-of-use price into six different time periods to improve the response sensitivity of the demand side resource. Interruptible load contracts can be divided into five different types, in one year, the interruption occurred time can reach $240 \mathrm{~h}$, fully improve the demand side of the utilization of resources. Norway response to the operating mode can be signed a variety of interruptible load contracts, the user can choose terminal price according to their own preferences. At the same time, demand-side resources can be achieved by competing with the generating units to participate in the frequency modulation capacity market to achieve power balance [8]. Most of the distribution networks in Finland have been able to apply dynamic real-time demand response, and have the application conditions of the real time price mechanism. Beginning in 2014, almost all the electricity demand respond to the user price will be used time-of-use price, which in order to slow down the power supply pressure, reduce the load curve peak played a positive role [9].

Table 1. Demand response measures of European countries.

\begin{tabular}{|c|c|c|}
\hline Region & Project type & Implementation mode \\
\hline \multirow[b]{2}{*}{ Britain } & TOU & Multiple TOU rates provided \\
\hline & interruptible load & $\begin{array}{l}\text { Interruptible load based contract form includes short term operating reserve, fast reserve and stability power grid } \\
\text { frequency response }\end{array}$ \\
\hline \multirow[t]{2}{*}{ Norway } & Interruptible load & $\begin{array}{l}\text { Based on advance notice time and duration at terminal, categories can be divided as below: (1) } 15 \text { minutes of advance } \\
\text { notice, without limit in interruption duration, load reduction rate of } 5 \% \text {; (2) } 2 \text { hours of advance notice, without limit in } \\
\text { interruption duration, load reduction rate of } 25 \% \text {; (3) } 15 \text { minutes of advance notice, } 2 \text { hours of interruption duration, } \\
\text { load reduction rate of } 75 \% \text {. Currently, the interruptible price for mode (1),(2) and (3) is respectively } 2.75 \text { euros } / \mathrm{kWh} \text {, } \\
10.83 \text { euros } / \mathrm{kWh} \text { and } 32.63 \text { euros } / \mathrm{kWh}\end{array}$ \\
\hline & demand side bidding & $\begin{array}{l}\text { Norwegian sea witnesses the development of electric power frequency regulating capacity market, so demand side } \\
\text { consumers can bid against power generation providers to regulate frequency and enable electric power balance. }\end{array}$ \\
\hline \multirow{2}{*}{ Finland } & TOU & $\begin{array}{l}\text { According to legislation, the electric power company shall use the mechanism of TOU, and a specific metering } \\
\text { system is designed }\end{array}$ \\
\hline & interruptible load & $\begin{array}{l}\text { Finland grid has signed an annual bilateral agreement with industrial users to obtain power demand side resources, } \\
\text { which are used as frequency regulation reserve and fast reserve. }\end{array}$ \\
\hline \multirow{2}{*}{ Spain } & TOU & $\begin{array}{l}\text { TOU includes prices in } 6 \text { different periods: critical peak pricing and flat electricity price during electrical peak } \\
\text { seasons, critical peak pricing and flat electricity price during middle seasons, and flat electricity price and valley } \\
\text { electricity price during valley seasons. }\end{array}$ \\
\hline & interruptible load & $\begin{array}{l}\text { Based on advance notice time ( } 0-2 \text { hours) and interruptible duration (1-12 hours), a contract can be divided into } 5 \\
\text { categories. In a year, an interruptible duration can reach } 240 \text { hours, with one interruption in a day at most and } 5 \text { in a } \\
\text { week at most. }\end{array}$ \\
\hline France & TOU & $\begin{array}{l}\text { Three kinds of electricity prices, namely, green electricity price for industrial users, yellow electricity price for tertiary } \\
\text { industry, and blue electricity price for resident, are based on RTP, peak-valley TOU and seasonal electricity prices. }\end{array}$ \\
\hline
\end{tabular}

Based on the analysis of the demand mechanism of foreign demand, we can provide reference for the operation mode of China's demand response. Based on the experience of foreign demand response, this paper will design the operation mode of China's demand response.

\section{Operation Mechanism Design of Demand Response in China}

China's current demand response mainly to orderly power utilization, in some areas the implementation of the 
peak-valley time-of-use price or interruption of load measures and other measures. With the deepening of the power system reform, China to strengthen and deepen the demand response must be based on the current work, the development of more measures and means, from the orderly transition to the demand side response mode. According to the actual needs of the market, the development of more demand response measures and means. Because of the adaptability and maturity of demand-side response measures in the context of market conditions, this determines that the demand-side response implementation model needs to evolve with the gradual improvement of market conditions at different stages. In other words, the demand-side response implementation model has a stage development attribute [10]. With the development of power market reform, the demand side response mode under different degree of marketization can be divided into the market primary stage mode, the transition stage model and the market perfect stage mode. As shown below.

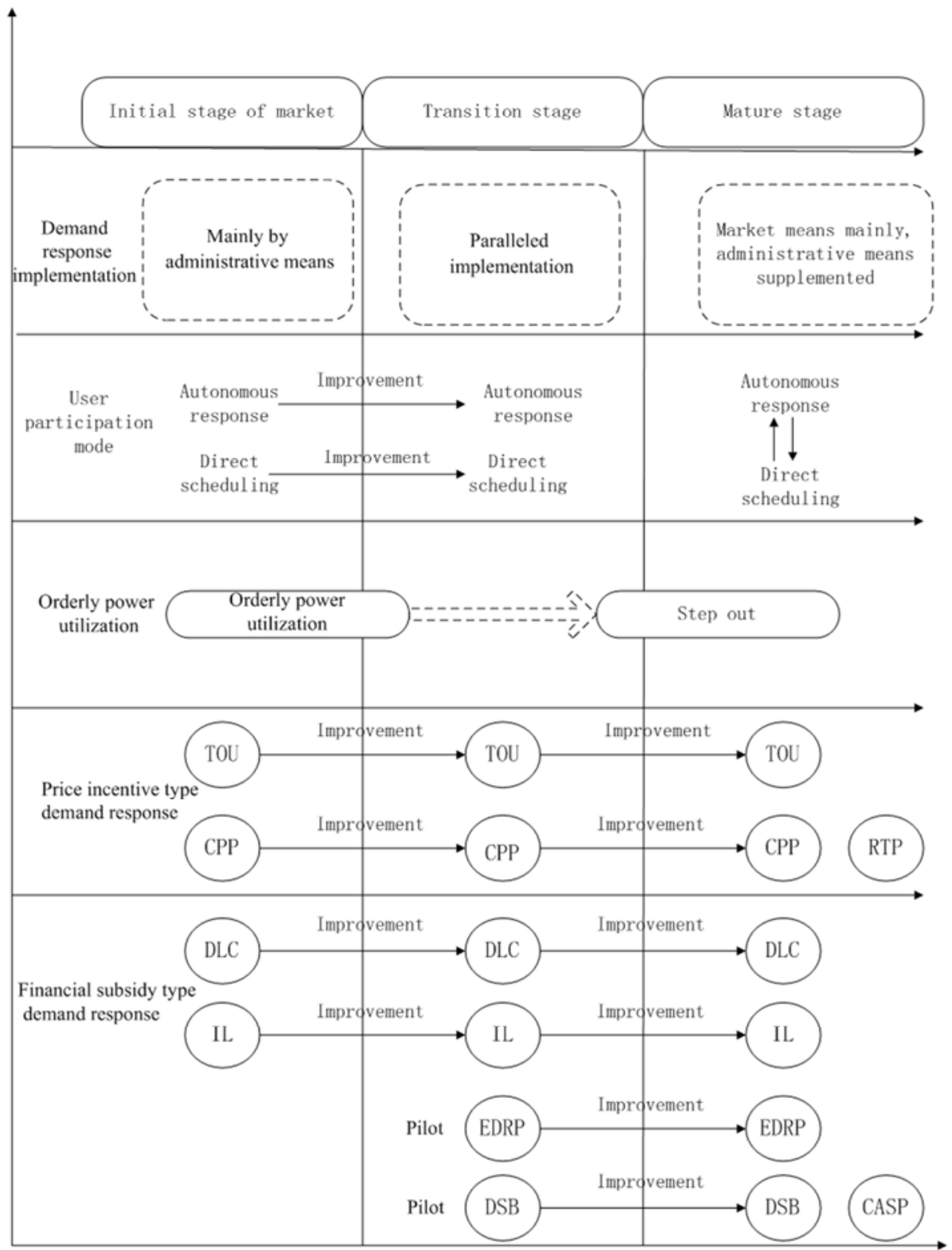

Figure 1. Roadmap to implement market-oriented demand response in China.

Note: TOU- Time of use price, CPP- peak price, RTP- real time price, DLC- direct load control, IL- interruptible load, EDRP- emergency demand response, DSB- demand side bidding, CASP- capacity / ancillary services

\subsection{DR Operation Mechanism in the Early Stage of Marketization}

In the initial stage of electric power market, due to imperfect market mechanism and relatively fewer electricity prices, the demand response implementation mode is still dominated by administrative means. Rely on the government's mandatory electricity management to ensure 
the safe and stable operation of the power system and gradually carry out the pilot work of the market means. In the early stages of price-based demand side response measures are mainly time of use electricity prices and peak price. The demand-side response measures based on incentives include direct load control and interruptible load. The user can participate in the demand response based on the price information published by the market operator or directly with the operator to issue a negotiable contract. At this stage the implementation of time-sharing price is mainly to carry out pilot work, the accumulation of time of use price implementation experience, time of use price as the demand side management work in addition to orderly electricity outside the auxiliary measures.

\subsection{Market Transition Period DR Operation Mechanism}

In the transition phase of the development of the electricity market, with the gradual development of the electricity market, the in-depth reform of the electricity price mechanism, the price form will begin to show the characteristics of diversification. In this case, demand-side response measures based on market prices will be promoted. However, due to the transitional stage of the price mechanism has not yet reached a sound and perfect level, it is impossible to rely solely on electricity price measures for load management, must retain a certain administrative means. Therefore, the transition stage should take the market means and administrative means parallel way, at the same time actively carry out the pilot work of the market means, and continue to broaden the scope of the implementation of market means.

In the transition phase, price-based demand-side response measures include both time of use and peak price. Demand side response based on Incentive includes direct load control, interruptible load, urgent demand response, demand side bidding, etc. Among them, the time of use price, peak price, interruptible load measures in the initial stage of the pilot work has accumulated a certain experience, on this basis, the transition phase of the time-sharing price, peak price, interruptible load will be widely used and direct load control as emergency measures to deal with emergencies. In addition, the transition phase will introduce emergency response requirements, demand side bidding two measures and carry out pilot work.

\subsection{Market Perfect Period DR Operation Mechanism}

In the power market to improve the stage, the power system market operation of a higher degree, the price mechanism is perfect, the electricity price measures are widely used. Users can through a variety of market-oriented price mechanism and market incentives, according to their own way to take the initiative to participate in market competition and access to the corresponding economic benefits. In this stage, the implementation mode of the demand side response will be based on the market means, supplemented by administrative means, supplemented by the power market mechanism to optimize the allocation of resources to achieve safe and stable power system, economic and efficient operation. In the market improvement stage, a higher degree of market, the price mechanism is sound, based on the pilot work and practical experience of the transition phase, the demand side responds to the development of various measures to mature. At this point, the system operators to provide users with a variety of measures to optimize the combination of the response program. Users can choose according to the program provided by the power company, take the initiative to participate in market competition.

\section{Demand Response Value Evaluation}

\subsection{Value Measurement Model}

DR mechanism aims to provide a system with a schedulable resource of cost competitiveness by changing the transient demand level in market, help a power system dispatching organization and a power supply enterprise effectively solve problems concerning shortage of system reserve capacity, power transmission congestion and poor regional power transmission and distribution capacity. When demand response (DR) can generate enduring load reducing ability, it can be served as a substitute resource on generation side for integrated planning to reduce construction investment in infrastructures of power generation, transmission or distribution. Benefits brought by implementing DR can be divided into economic benefit and environmental benefit. See table 2 for details.

Table 2. Economic benefit and environmental benefit brought by DR project.

\begin{tabular}{|c|c|c|}
\hline Type & Name & Description \\
\hline \multirow{5}{*}{$\begin{array}{l}\text { Economic } \\
\text { benefit }\end{array}$} & Reduce power demand & $\begin{array}{l}\text { Users can reduce electric energy demand in a relative or absolute way by changing } \\
\text { energy-efficient equipment and improving production process, procedure and so on. }\end{array}$ \\
\hline & $\begin{array}{l}\text { Avoid or postpone investment in new power } \\
\text { plant }\end{array}$ & $\begin{array}{l}\text { DR resources can be used to reduce the peak load of system, reduce system capacity } \\
\text { demand and avoid or postpone investment in new power plant. }\end{array}$ \\
\hline & Reduce the power supply cost of the system & $\begin{array}{l}\text { Peak load dropping can reduce the using frequency of system backup units and } \\
\text { further reduce the power supply cost in peak period. }\end{array}$ \\
\hline & $\begin{array}{l}\text { Reduce construction investment in power } \\
\text { transmission and distribution }\end{array}$ & $\begin{array}{l}\text { Dropping of peak load demand can effectively reduce power transmission } \\
\text { congestion and save investment in transmission and distribution lines. }\end{array}$ \\
\hline & Increase system reliability & $\begin{array}{l}\text { DR resource can offer fast capacity reserve, enhance power reliability, and avoid } \\
\text { losses arising from production and service interruption in emergency. }\end{array}$ \\
\hline \multirow{2}{*}{$\begin{array}{l}\text { Environmental } \\
\text { benefit }\end{array}$} & Promote new energy absorption & $\begin{array}{l}\text { DR resource has the stand-by storage function to restrain the fluctuation of new } \\
\text { energy output in system and enhance the absorption ability of new energy. }\end{array}$ \\
\hline & Reduce emission of pollutants & $\begin{array}{l}\text { As a clean demand side resource, DR can effectively reduce the emission load of } \\
\text { hazardous substances such as } \mathrm{CO}_{2}, \mathrm{SO}_{2} \text { and oxynitride. }\end{array}$ \\
\hline
\end{tabular}


Therefore, DR project development will achieve the goal of optimum distribution of electric power resources in our country and of energy conservation and emission reduction in electric power industry. Moreover, DR project is also a countermeasure to enhance the stability level and operation efficiency of the whole electric power market. Construction and improvement in the electric power market can't stand away from coordination and operation of supply side and demand side resources. Such kind of project can be developed to help the market build a price discovery mechanism as soon as possible. According to the prediction from Navigant Research - an American market research institution, by 2023, the global power demand response capacity will exceed $196.6 \mathrm{GW}$, and booming development of new energy and renewable energy sources will also bring unprecedented opportunities for development of power demand response.

According to integrated efficiency analysis for DR, this section is intended to calculate the implementation efficiency for DR project, from the angle of project implementer and based on benefit-cost analysis method. The involved data variable definition is shown below:

(1) Total number of regional power consumer $(\mathrm{N})$

(2) Consumer's participation rate $\gamma(\%)$

(3) Avoidable capacity Pt (KW)

(4) Avoidable capacity electric quantity $\Delta E c(\mathrm{KW})$

The avoidable capacity electric quantity refers to the generated energy to be avoided at supply side driven by terminal node, with its computational formula shown below

$$
\Delta E_{c}=\frac{\Delta E_{o}}{(1-\phi)(1-\beta)(1-\alpha)}
$$

Wherein, $\Delta E_{c}-$ The avoidable electric quantity of system;

$\Delta E_{o} \longrightarrow$ Electric quantity saved by power consumer due

to implementation of power saving measures;

$\alpha-$ Loss coefficient of power grid transmission and distribution power;

$\phi-$ Loss coefficient of terminal distribution power of electric power system;

$\beta-$ Station service power consumption rate

(5) Cost of Management - CM (yuan)

Cost of Management refers to all expenses incurred by electric power company to manage and organize DR activities. If Cost of Management is amortized as per avoidable capacity, its computational formula is shown below, with Cost of Management per unit set as $\mu$

$$
C_{M}=P_{t} \times \mu
$$

(6) Equipment cost $C_{f}$ (yuan)

DR equipment cost comprises the sum of acquisition expenses (for hardware and software system installed for control equipment, communication equipment and control center) and construction \& installation charge, with computational formula shown below

$$
C_{f}=C_{1} \times N+C_{2} \times N+C_{3} \times N+C_{4} \times M
$$

Wherein, $\mathrm{C} 1$ Cost of single piece of control equipment;

$\mathrm{C} 2-$ Cost of single piece of communication equipment (receiver and transmitter);

C3 - Cost paid for equipment installation;

$\mathrm{C} 4$ Construction cost for hardware and software system in control center

Generally, C1, C2 and C3 are calculated as per one household and one piece of equipment, while $\mathrm{C} 4$ is calculated as per the number of units of control center in the area

\section{(7) Operation and maintenance cost $C_{o M}$ (yuan)}

The operation and maintenance cost for DR project is divided into electric quantity cost and capacity cost. The former refers to energy-saving subsidy and incentive for consumer (variable cost) and is confirmed as per tariff subsidy level; capacity cost is used to pay for capacity construction (fixed cost), with details shown below

$$
C_{O M}=\Delta E_{c t} \times \alpha+P_{t} \times \beta \times 15 \%
$$

Wherein, $\alpha-$ Level of tariff subsidy granted to power consumer by DR project;

\section{$\beta$ - Level of capacity tariff}

According to foreign experiences, the operation and maintenance cost for capacity can be calculated by $15 \%$ of the capacity tariff.

(8) Avoidable power consumption cost

The avoidable power consumption cost mainly comprises the avoidable capacity cost $\mathrm{CP}$ (fixed cost) and the avoidable electric quantity cost $\mathrm{CE}$ (variable cost). The former refers to investment cost reduced by power enterprise for unit or power grid and can be confirmed based on the average cost for unbuilt or suspended power plant, substation and power transmission line; the latter can be confirmed based on the average purchase tariff. The computational formulas for $\mathrm{CP}$ and $\mathrm{CE}$ are shown below:

$$
\begin{aligned}
C_{P}= & P_{t} \times \theta \\
& C_{M}=P_{t} \times \mu
\end{aligned}
$$

Wherein, $\theta-$ Conversion factor for the avoidable capacity cost, which can be obtained by amortizing annual reduced investment cost to the avoidable capacity cost;

$\omega-$ Conversion factor for the avoidable electric quantity, with the computing unit of yuan $/ \mathrm{kWh}$.

$\kappa$ - User side purchase price

(9) Emission reduction benefit (yuan) 
The DR project can be implemented to partially substitute thermal power generation, which in turn promotes emission reduction of $\mathrm{CO}_{2}, \mathrm{SO}_{2}$ and $\mathrm{NO}_{\mathrm{x}}$. According to the energy savings obtained from the DR project, relevant emission factor or coefficient can be confirmed to get actual emission reductions of main emissions. According to the report on the People's Republic of China National Greenhouse Gas Inventory, emission factors of air pollutants $\left(\mathrm{SO}_{2}, \mathrm{NO}_{\mathrm{x}}\right)$ arising from Chinese thermal power generation are respectively $8.03 \mathrm{~g} / \mathrm{kWh}$ and $6.90 \mathrm{~g} / \mathrm{kWh}$. The emission factor of $\mathrm{CO}_{2}$ is related with fuel category. By reference to the Main pollutant emission from 1 ton of combusted coal in thermal power plant, we can get emission reduction value of 130 yuan/t for $\mathrm{CO}_{2}, 6000$ yuan/t for $\mathrm{SO}_{2}$ and 8000 yuan/t for $\mathrm{NO}_{\mathrm{x}}$.

Total emission reduction benefit refers to the product sum of emission reductions multiplied by emission reduction values of $\mathrm{CO}_{2}, \mathrm{SO}_{2}$ or other pollution gases, with computational formula shown below

$$
\begin{aligned}
& V_{r}=N_{\mathrm{CO}_{2}} \times V_{\mathrm{CO}_{2}}+N_{\mathrm{SO}_{2}} \times V_{\mathrm{SO}_{2}}+N_{\mathrm{NO}_{x}} \times V_{\mathrm{NO}_{x}} \\
& =\Delta E_{C} \times \rho \times 130+\Delta E_{C} \times \rho \times 6000+\Delta E_{C} \times \rho \times 8000
\end{aligned}
$$

Wherein, $V_{r}$ Annual total emission reduction benefit $N_{\mathrm{CO}_{2}}, N_{\mathrm{SO}_{2}}, N_{\mathrm{NOx}}-$ Emission reductions of $\mathrm{CO}_{2}$, $\mathrm{SO}_{2}$ and $\mathrm{NOx}$

$V_{\mathrm{CO}_{2}}, V_{\mathrm{SO}_{2}}, V_{\mathrm{NOx}}-$ Unit emission reduction values of $\mathrm{CO}_{2}, \mathrm{SO}_{2}$ and NOx

$\rho \_$Emission reduction coefficient of $\mathrm{CO}_{2}$, which can be selected as per fuel category

\subsection{Case Analysis}

The cost-benefit analysis aims to use the ratio of full cost to the entire earnings for project as an economic decision-making method to measure project feasibility. This paper, based on a DR project implemented for consumers in architectural complex in a certain area of Shanghai, is intended to measure the implementation effect of the project according to cost-benefit analysis idea.

(1) Project introduction and basic data

There are 21,030 consumers in the commercial district. Motivated by governmental publicity, about $30 \%$ of the consumers are willing to attend the DR project. With six years as the project implementation period, the annual time length for consumers to attend DR project is $42 \mathrm{~h}$ and annual avoidable capacity is $700000 \mathrm{~kW}$. The research group, by interview, data statistics and other ways, has collected basic data such as cost required for implementation of DR project and pollution gas emissions, with details shown below:

The unit administration expense can be amortized as per avoidable capacity and shall be 80 Yuan $/ \mathrm{kW}$.

Equipment cost includes the acquisition cost and construction and installation cost for hardware and software system installed for control equipment, communication equipment and control center, which are shown below: control equipment: 30000 Yuan/household (one for each household); communication equipment: 2800 Yuan/household (mainly including receiver; current communication network for electric power system can be available); control center: 2.1 million Yuan/unit (22 units required for the area); construction and installation cost: equally shared by each household, namely, 750 Yuan/household.

In the operation and maintenance cost, the tariff subsidy for electric quantity shall be calculated as per $0.4 y u a n / \mathrm{kWh}$; the capacity tariff for capacity shall be calculated as per $35 y u a n / k V A$.

The avoidable capacity cost shall be calculated as per the value computed based on the unit cost of domestic pumped storage power station (10\% discount rate, on 20 -year basis). The unit cost for the current domestic pumped storage power station is about $3000 \mathrm{Yuan} / \mathrm{kW}$, so the annual value of the unit cost is 704 yuan/kW. Power supply side to avoid the cost of electricity due to the impact of raw material prices, assuming 0.42 yuan $/ \mathrm{kWh}$, the main users of the region for commercial users, the user side to avoid the cost of electricity 0.93 yuan / kWh.

Anthracite is the main fuel for power generation in the area, so emission reduction coefficients of main exhaust gases are $335.7 \mathrm{~g} / \mathrm{kWh}\left(\mathrm{CO}_{2}\right), 8.03 \mathrm{~g} / \mathrm{kWh}\left(\mathrm{SO}_{2}\right)$ and $6.9 \mathrm{~g} / \mathrm{kWh}\left(\mathrm{NO}_{\mathrm{x}}\right)$; corresponding emission reduction values are 130 Yuan/t $\left(\mathrm{CO}_{2}\right), 6000$ Yuan/t $\left(\mathrm{SO}_{2}\right)$ and 8000 Yuan/t $\left(\mathrm{NO}_{\mathrm{x}}\right)$

(2) Calculation process

Cost-benefit ratio can better reflect advantage arising from implementation of DR, with detailed steps shown below:

Step 1: The operating years for DR project is $t$, and the remanent value of equipment at the end of the Year $n$ is Vs (According to Circular of State Administration of Taxation on Acknowledging the Execution Time for Enterprises to Adjust the Proportion of the Scrap Value of Fixed Assets, the scrap value of fixed assets shall be generally defined as 5\%), so Total Revenue (TR) for DR project in $n$ years is calculated as below:

If time value (dynamic evaluation) is considered, the basic discount rate will be $\mathrm{i}_{0}$ (the basic discount rate under dynamic evaluation is $8 \%$ ), with computational formula shown below

$$
T R=\sum_{t=1}^{n}\left(C_{P}+C_{\Delta E}+V_{r}\right)\left(1+i_{0}\right)^{-t}+V_{S}, i=1,2,3 \ldots \ldots n
$$

From formula (8), it is known that, the DR benefit formula is composed of avoidable capacity, avoidable electric quantity, emission reduction benefit, reduced reserve capacity benefit and remanent value of equipment. With the avoidable capacity of $700000 \mathrm{KW}$ given, we can get annual electric quantity of $29400000 \mathrm{kWh}$ according to formula (1). The avoidable electric quantity and the avoidable capacity can be converted to supply-side avoidable cost as per formula (5) and (6); reduced pollution gas emissions can be converted to economic benefit as per formula (7). Finally the Total Revenue of DR project can be formed. 
Step 2: Similarly, the operating years for DR project is $t$, so the Total Cost (TC) of DR project in $n$ years is calculated as below

If time value (dynamic evaluation) is considered, the basic discount rate will be $\mathrm{i}_{0}$, with computational formula shown below

$$
T C=\sum_{i=1}^{n} C_{M}\left(1+i_{0}\right)^{-t}+C_{f}+\sum_{i=1}^{n} C_{O M}\left(1+i_{0}\right)^{-t}, i=1,2,3 \ldots . ., \mathrm{n} . .
$$

From formula (9), it is known that, the DR cost formula is composed of administration expense, equipment cost and operation and maintenance cost. Based on the control equipment, communication equipment and control center as well as their software system which are required for DR. Calculate the initial cost of the hardware in accordance with formula (3). Then, based on the avoidable capacity and avoidable electric quantity as well as the conversion rate, we can calculate administration expense and operation and maintenance cost required for DR to form the total cost for DR project as per formula (4) and (2).
Step 3: It's required to analyze the project feasibility by benefit-cost ratio. If the ratio is more than 1 , and the benefit is more than the cost, the project will be regarded as a feasible one with cost-effectiveness; conversely, if the ratio is less than 1, and the benefit is less than the cost, the project will be regarded as an infeasible one without cost-effectiveness. Meanwhile, the bigger the ratio, the higher the benefit for the project.

If time value (dynamic evaluation) is considered, the computational formula will be shown below

$$
B C R=\frac{T R}{T C}=\frac{\sum_{t=1}^{n}\left(C_{P}+C_{\Delta E}+V_{r}\right)\left(1+i_{0}\right)^{-t}+V_{S}}{\sum_{i=1}^{n} C_{M}\left(1+i_{0}\right)^{-t}+C_{f}+\sum_{i=1}^{n} C_{O M}\left(1+i_{0}\right)^{-t}}
$$

Based on the above data, the analysis of the cost-benefit calculation for DR project implemented by the electric power company in the area is shown below

\begin{tabular}{|c|c|c|}
\hline Computational item & Assumed condition & Value (10 thousand yuan) \\
\hline Total cost & & 54652.2 \\
\hline Administration expense & 80 yuan $/ \mathrm{kW}$ & 25888.1 \\
\hline Control equipment & 30000 yuan/household & 18927 \\
\hline Receiver & 2800 yuan/household & 1766.5 \\
\hline Installation cost & 750 yuan/household & 473.2 \\
\hline Control center & 22 units, 210000 yuan /unit & 462 \\
\hline \multicolumn{3}{|l|}{ Operation and maintenance cost } \\
\hline Capacity & Calculated as per $15 \%$ of the capacity tariff ( 35 yuan $/ \mathrm{kVA}$ ) & 1698.9 \\
\hline Total Revenue & & 248605.4 \\
\hline Avoidable capacity cost & 704 yuan $/ \mathrm{kW}$ & 227815.5 \\
\hline Avoidable electric quantity cost & & 8834.3 \\
\hline Power supply side & 0.42 yuan $/ \mathrm{kWh}$ & 5708.3 \\
\hline User side & 0.93 yuan $/ \mathrm{kWh}$ & 12639.9 \\
\hline Emission reduction cost for $\mathrm{CO}_{2}$ & $335.7 \mathrm{~g} / \mathrm{kWh}, 130$ yuan $/ \mathrm{t}$ & 593.2 \\
\hline $\mathrm{SO}_{2}$ & $8.03 \mathrm{~g} / \mathrm{kWh}, 6000$ yuan $/ \mathrm{t}$ & 654.8 \\
\hline Remanent value of equipment & Calculated as per $5 \%$ of the original value & 2168.9 \\
\hline Benefit-Cost Ratio & & 4.5 \\
\hline
\end{tabular}

Table 3. Calculation for the benefit ratio for DR project (dynamic evaluation in the operation period).

According to the calculating results, we can obtain BCR (=4.4) for implementing DR project in the area. This shows higher feasibility to implement DR project in the area.

User engagement is an important index to measure the success of a DR project. With enhancement of users' cognition level, the participation rate of users will increase to result in continuous expansion of saved avoidable capacity, avoidable electric quantity and relevant environmental benefit as well as higher and higher benefit-cost ratio.

\section{Conclusion}

China's power system is being transformed from the planning system to the market system, with the improvement of the power market mechanism, the sale of electricity companies, DR aggregators are able to participate in the implementation of DR, DR implementation of the main body more diversified. At the same time the market mechanism makes the energy trading center emerging, which will have a greater impact on the implementation of the DR process.

Based on the analysis of the operation mode of foreign demand response, this paper designs the demand response mechanism under the Chinese market mechanism, divides the operation mode of demand response in China into three stages, and puts forward the concrete implementation mode. Based on the cost-benefit analysis method, the economic value of the demand response is evaluated and specifically measured the Shanghai area of a building complex in the implementation of the demand response project benefit ratio of 4.5. The research results can provide decision support for demand response mechanism design and demand response mining in power market reform. 


\section{References}

[1] US Department of Energy. Benefits of demand response in electricity markets and recommendations for achieving them: a report to the United State Congress pursuant to section 1252 of the Energy Policy Act of 2005 [R/OL]. [2008-02-21]. $\mathrm{http} /$ www.ferc.gov/legal/staff-reports/12-08-demand-response. pdf.

[2] Zeng Ming, Sun Xin, Zhang Qiping, Lv Zhaomin, Li Tao. Study on incentive mechanism and policy suggestion of power demand side management in China [J]. Power Demand Side Management, 2003, (02): 3-6.

[3] Federal Energy Regulatory Commission. Assessment of demand response and advanced metering; 2006 staff report [EB/OL]. [2010-03-20] (2013-01-10). http://www.ferc.gov/legal/staff-reports/demandresponse.

[4] Tao Xiaoma, Zhou Wen. Research progress and literature review of power demand response [J]. Journal of Beijing Institute of Technology (Social Science Edition), 2014, (01): $32-40$.

[5] Us Department of Energy. Benefits of demand response in electricity markets and recommendations for achieving them: a report to the United States congress pursuant to section 1252

of the energy policy act of 2005 [EB/OL]. (2006-02) [2013-01-10].

[6] Ruan Wenjun, Liu Sha, Li Yang. Overview of US demand response [J]. Power demand side management, 2013, (02): 61-64.

[7] Pei Lijun. US and Japan demand response mode of operation and incentive mechanism [J]. Power demand side management, 2013, (02): 57-60.

[8] Zhao Yan, Li Bo Song, Jiang Chuanwen. Under the conditions of open electricity sales under the conditions of China's demand side resources to participate in the power market operating mechanism of the proposed [J]. Power Construction, 2016, (03): 112-116.

[9] Li Guodong, Liu Lihua, Fu Xueqian. Development of electricity demand side management in Finland [J]. Demand Side Management, 2014, 16 (1): 61-64.

[10] Lu Yinming. China's power demand side response model method and implementation model [D]. North China Electric Power University (Beijing), 2010.

[11] Huo Molin, He Sheng. Electric power market reform on the impact of demand response [J]. For electricity, 2017, (03): $16-20+15$. 